\section{Plasma Physics in Britain}

THe Science Research Council has now published the review of plasma physies which it commissioned at the beginning of 1967. Most of the hard work in the report was carried out by Dr P. A. Davenport, who was seconded to the SRC from the UKAEA Culham Laboratory, and the review is the responsibility of the Plasma Physics Panel of the SRC, under the chairmanship of Dr R. S. Pease, director of Culham. But, unlike the recent SRC report on astronomy, this report is no exercise in special pleading-indeed, it makes scarcely any attempt to argue the case for plasma physics or for more fusion research. It simply records the scope and range of the plasma physics teaching and research in Britain, including the work done in industry. As a work of reference, it will clearly be of very great value. As a means of persuading governments to spend more on research of this sort, it is less successful.

The report does contain, however, a league table of international expenditure on fusion research which shows that British levels of spending are far from extravagant. Expenditure in the United States and in the USSR is of course much higher, but West Germany also rates higher than the United Kingdom, and France seems likely to do so within the next few years.

The report spreads its net wide-so wide, indeed, that it admits that there may be a significant overlap with areas which might more properly be called atomic or space physics. First, it classifies plasma physics into seven main categories-natural plasmas, laboratory plasmas, basic studies using plasmas, research technology using plasmas, plasmas used as circuit elements, chemical and process engineering and finally power production and energy conversion. This broad definition has brought to light no fewer than 340 postgraduate students who are at present engaged on $\mathrm{PhD}$ courses, and the report estimates that the annual output of PhDs in plasma physics by 1970 will be eighty. Over half of these will continue in higher education and research, if the figures in the report are any guide. Analysis of a group of students from a number of British universities shows that 53 per cent of plasma physics PhDs went on to higher education and research, while 9 per cent went into schools, colleges and teacher training. Seventeen per cent went into industry and 15 per cent into the Government service.

In British universities, by far the greater part of the research falls into the basic sector, a finding which need surprise nobody. It is noticeable, however, that very little university research seems to be relevant to power and energy, the areas which provide most of the practical applications of the subject and much of the intellectual drive. Most of those interested in the development of fusion power stations and magneto-

\begin{tabular}{|lcc|}
\hline \multicolumn{1}{c|}{ FUSION RESEARCH } & Annual \\
Country & fm p.a. & $\begin{array}{c}\text { growth } \\
\text { (per cent) }\end{array}$ \\
United Kingdom & $3 \cdot 8$ & -10 \\
USA & 14 & +15 \\
USSR & c. 20 & \\
West Germany & 5 & +20 \\
France & 3 & Rapid \\
Japan & $0 \cdot 4$ & expansion \\
& & \\
\hline
\end{tabular}

hydrodynamic power generation seem to have been mopped up by Culham and the several industrial laboratories which are interested. But although the biggest potential market for plasma technology is in these areas, the report names several other possible markets. Mercury arc valves for direct current electricity transmission, gas discharge lamps, plasma torches, electrically augmented flames for use in the steel industry and gas lasers are all in some way dependent on a knowledge of how plasmas behave. The greatest growth point, the report suggests, is in plasma physics related to space and astronomy research, since "most matter outside the immediate surface of the Earth is in the plasma state". It makes the point that there is growing interest in the study of

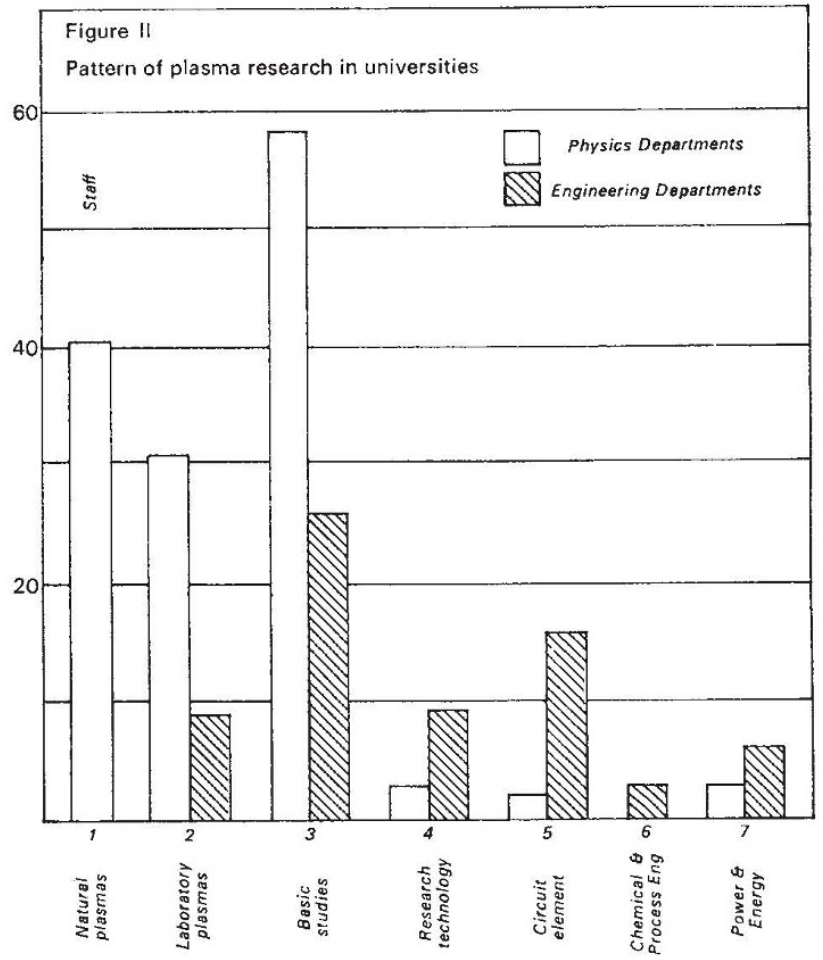

the dynamics of highly ionized plasmas on the laboratory scale. Experiments of this sort, it suggests, could well be relevant to the interpretation of astrophysical and space data, but very few yet seem to have been done in Britain. This area, the report recommends, well merits SRC encouragement and support, as a complement to the present space research programme.

In its recommendations, the panel states its belief that it would be desirable to introduce plasma physics at an earlier stage in education, at some time during the undergraduate course. In the future, it adds, it is likely that the scale of support offered by the SRC to universities ( $£ 150,000$ a year at the moment) will need to be increased, while at the same time universities should develop and encourage their contacts with industry. The panel also says that the SRC should continue to discuss with the UKAEA what is to become of the basic work on the physics of highly ionized plasmas which has hitherto been carried out by the AEA. 